\title{
Retrospectiva e Perspectivas da Repressão aos Abusos do Poder Econômico no Brasil
}

\author{
J. G. Piquet Carneiro
}

Advogado e Professor universitário

(PUC-GB)

SUMÁRIO: I - Breve histórico; Abstração versus realidade; II - O fracasso da política antitruste no Brasil; 1. Flexibilidade judiciária ou rigor legislativo; 2. Política antitruste e liberalismo econômico; 3. Política antitruste e tipos de mercado; 4. A deformação funcional da CADE; III - Sugestōes.

\section{I - BREVE HISTÓRICO}

A origem da legislação antitruste no Brasil encontra-se nos dispositivos que tratam dos crimes contra a economia popular. A idéia de proteção da economia popular foi introduzida pela Constituição de 1934 e ampliada pela de 1937 onde os delitos "foram equiparados aos crimes contra o Estado, devendo a lei cominar-lhes penas graves e prescrever-lhes processo e julgamento adequados a sua pronta e segura punição".

Esse dispositivo da Carta de 1937 foi regulamentado pelo Decreto-lei $n .^{\circ} 869$, de 18 de novembro de 1938. Conforme declarou Francisco Campos, em 18 de novembro de 1938, o objetivo da lei foi "evitar o bloqueio da concorrência por meio de arranjos, combinações, organizações destinadas a estabelecer um monopólio em certos ramos da economia pública ou a restringir a livre competição indispensável ao desenvolvimento industrial e comercial do país".

Apesar da amplitude dos dispositivos do Decreto-lei $n .869$, eles não foram executados no que tange às práticas monopolís- 
ticas. Apenas em um único caso a Consultoria-Geral da República, respondendo a uma consulta da Standard Oil Company of Brazil, opinou no sentido de que certas cláusulas de um determinado contrato com proprietários de postos de gasolina eram ilicitas. Em decorrência, o Presidente Getúlio Vargas aprovou o parecer e determinou que a empresa deveria "modificar seus contratos e instruções no sentido de submeter-se à lei que define os crimes contra a economia popular". No entanto, nessa época ainda não se cogitava da criação de um órgão destinado a implementar os dispositivos referentes a atividades monopolísticas, que permaneceram letra morta.

Em 1945, o então Ministro da Justiça Agamemnon MagaIhães foi o autor intelectual do Decreto-lei n. 7.666 , de 22 de junho (conhecido como a "Lei Malaia"), dispondo especificamente sobre abusos do poder econômico. Pouco aepois, com a queda do governo, o Decreto-lei n. 7.666 foi revogado. Entretanto, serviu de base para inspirar o artigo 148 da Constituição Federal de 1946:

“A lei reprimirá toda e qualquer forma de abuso do poder econômico, inclusive as uniões ou agrupamentos de empresas individuais ou sociais, seja qual for a sua natureza, que tenham por fim dominar os mercados nacionais, e eliminar a concorrência e aumentar arbitrariamente os lucros".

Em abril de 1948 foi ainda Agamemnon Magalhães, como deputado, quem encaminhou o projeto $n .^{\circ} 122$, regulamentando o preceito constitucional. Decorridos doze anos intercalados por períodos de pomposas apologias e de total esquecimento, o Congresso aprovou, afinal, a Lei $n .^{\circ} 4.137$, em 10 de setembro de 1962.

A Constituição de 1967 manteve dispositivo semelhante com pequenas aduptações formais, cuja redação (Emenda Constitucional de 1969) é a seguinte:

"Art. 160 - A ordem econômica e social tem por fim realizar o desenvolvimento nacional e a justiça social, com bases nos seguintes princípios:

- Nesta exposição os termos e expressões "práticas monopolisticas" e "sistema antitruste" săo usados em sentido lato, compreendendo, năo apenas monopólios e trustes, mas toda a ampla variedade de práticas consideradas abusivas. 


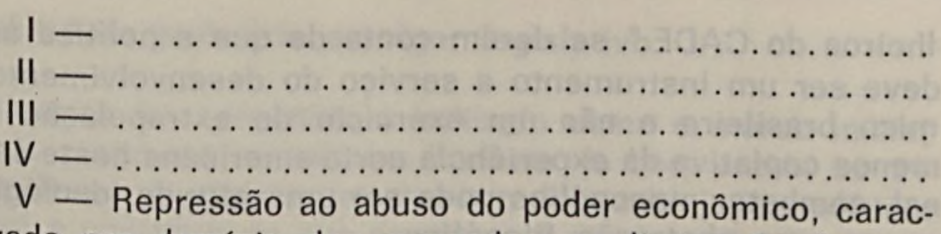

terizado por domínio dos mercados, a eliminação da concorrência e o aumento arbitrário dos lucros;

VI

\section{Abstração versus realidade}

Essa rápida visão retrospectiva do "movimento" antimonopolístico no Brasil permite extrair conclusões de caráter genérico, que revelam alguns vícios de formulação típicos da mentalidade econômico-jurídica no Brasil. Em primeiro lugar, causa estranheza a inserção de um dispositivo especifico na Constituição Federal sobre a repressão de comportamentos econômicos abusivos. Tanto assim que o Decreto-lei n..$^{\circ} 869$, anteriormente referido, jamais teve sua constitucionalidade posta em dúvida, na parte em que regula essa matéria. Se encarado do ponto de vista econômico liberal, esse controle é da própria essência de uma economia de mercado e encontra respaldo nos princípios gerais da Constituição sobre a organização econômica. Examinado sob este ângulo, o artigo 148 da Constituição de 1946, assim como o artigo 160 da Constituição de 1967, são uma redundância desnecessária; diria, até, que revelam, dentre outras coisas, falta de visão econômica do problema. Além do mais, esse tipo de norma constrange o campo de atuação do de incompatibilidades entre a lei ordinária e a Constituição.

Nota-se, em segundo lugar, que as forças capazes de introduzir um dispositivo constitucional específico não conseguiram executar na prática aquilo que alcançaram no plano teórico. Analisando "esses dois aspectos, conclui-se que a "inspiração" antitruste não foi autêntica, no sentido de que lhe faltou a motivação econômica real. Assim, não correspondeu a um anseio ditado por necessidades concretas do nosso quadro social e econômico, limitando-se a uma conquista que se esgotou no plano jurídico. Nem o constituinte, nem o legislador, nem os conse- 
Iheiros do CADE * se deram conta de que a política antitruste deve ser um instrumento a serviço do desenvolvimento econômico brasileiro e não um exercício de extrapolação mais ou menos copiativa da experiência norte-americana neste setor. Afinal, combater monopólios pode ser uma atitude ideológica, mas nunca uma abstração filosófica.

\section{II - O FRACASSO DA POLÍTICA ANTITRUSTE NO BRASIL}

Não pretendo deter-me na apreciação dos óbices administrativos que têm atravancado a atuação real ou potencial do CADE. Eles são evidentes e podem ser diagnosticados sem maior dificuldade (debilidade orçamentária e técnica, falta de apoio governamental, obsolescência do sistema de informação e coleta de dados, etc.). Ao contrário, pretendo apontar algumas causas substanciais, jurídicas e econômicas, que impedem ou dificultam a implantação de um sistema autônomo de controle dos abusos do poder econômico no Brasil. Assim procedendo, não descarto, de antemão, a possibilidade de que tal sistema possa ser inviável na forma em que se encontra atualmente proposto.

O fracasso da experiência antitruste no Brasil não é, de forma alguma, um fenômeno isolado. Em todos os países latinoamericanos, que contam com legislações antimonopolísticas, as conquistas foram muito modestas, quando não também de insucesso total. Na Europa, salvo, talvez, ao nível do Mercado Comum, o combate aos abusos do poder econômico não teve grande sucesso, sendo que na Itália não existe, sequer, legislação específica sobre a matéria. Realmente, foi nos Estados Unidos (e, em parte, na Inglaterra) que a politica antitruste encontrou aplicação prática e eficiente.

A explicação para esse fenômeno ainda não está suficientemente estabelecida e poucos estudiosos têm se aprofundado no assunto. Em todo caso, há certas causas imediatas e evidentes que podem ser, desde logo, apontadas por meio da comparação entre os sistemas jurídico, político e econômico do Brasil e dos Estados Unidos, com ênfase nos aspectos que nos distinguem fundamentalmente deste último. Conselho Administrativo de Defesa Econômica, criado pela Lei $n 0^{\circ} 4.137$, de 10 de
setembro de 1962 . 


\section{Flexibilidade judiciária ou rigor legislativo}

O Sherman Act, de 1890, é indicado como o marco inicial do sistema antitruste americano. Todavia, já bem antes, os tribunais ingleses e americanos haviam formado jurisprudência expressiva e coerente no que concerne à condenação de certas práticas monopolísticas e abusivas. Sob esse aspecto o Sherman Act e, posteriormente, o Clayton Act nada mais foram do que a condensação de experiências judiciárias anteriores que, por motivos políticos e econômicos, necessitavam de maior organicidade. Assim, quando o legislador americano se pronunciou pela primeira vez sobre o assunto, atendendo à pressão política dos agricultores atingidos por vários tipos de trustes, a tradição judiciária já se encontrava sedimentada.

Além disso, o sistema "Common Law" prescindiu de legislação específica para reprimir os comportamentos abusivos dos participantes no mercado. Bastou a flexibilidade das próprias Cortes (esse resíduo de "poder legislativo" do juiz, que se afigura tão incompreensivel do ponto de vista do nosso sistema "nulta poena sine lege") e um estatuto singelo para se desencadear o mecanismo de controle judicial. No Brasil, ao contrário, a Lei $n .{ }^{\circ} 4.137$ cometeu o grave engano de buscar a conceituação prévia, analítica e apenas jurídica, das várias formas de abuso do poder econômico. Isso conflita com duas realidades ligadas à aplicação da lei, uma vez que: (a) o abuso do poder econômico, como o próprio nome indica, não se origina da violação de um princípio puramente jurídico, mas de um "acontecimento" que interfere com as regras do jogo econômico (em matéria antitruste uma certa situação pode ser válida do ponto de vista puramente jurídico, mas condenável sob o prisma econômico porque atua como entrave à eficácia do mercado); (b) a riqueza e o dinamismo das relações econômicas exigem regras sintéticas e maleáveis porque é impossivel estabelecer, de antemão, as múltiplas modalidades de fenômenos que se pretende regular, e que a inventiva dos participantes do mercado não cessa de criar. Neste particular, a experiência americana é esclarecedora, pois raramente as hipóteses se repetem, o que conduz a uma administração casuística da justiça econô-
mica.

Quando se analisa o enfoque adotado pelo CADE, esses problemas surgem com perfeita nitidez. Primeiro, ao tentar enquadrar o delito apontado sob a ótica apenas jurídica (qual teria 
sido a vontade das partes, se houve intenção dolosa, ou boa fé, etc.) o conselheiro esbarra com um problema terrivel de prova. Ao contrário, no sistema americano a abordagem é, em regra, pelo ângulo econômico. A repercussão econômica concreta ou potencial de um determinado comportamento é que indicará a conveniência ou não de coibir a sua prática, enquanto que a vontade do agente entra como elemento apenas subsidiário. Em matéria antitruste a boa intenção não deve assegurar a condescendência da Corte. Este último enfoque econômico permite, por outro lado, despir o ato abusivo de conotações depreciativas ou infamantes para quem o pratica.

Além do mais, a definição analítica legal impede que o CADE amolde a regra ao caso concreto, já que, na maioria das vezes, há algo de inédito na forma de manipulação do poder. Com isso, permite-se que o infrator potencial opte por práticas que contornam o rigor literal do texto e the asseguram a impunidade. A lei perde, assim, a sua virtude de coação moral, impedindo, paradoxalmente, que se faça justiça.

\section{Política antitruste e liberalismo econômico}

A política antitruste é filha legítima da economia de mercado e surgiu e prosperou na fase áurea do liberalismo econômico americano. Até hoje é apontada como a melhor forma de resguardar a liberdade de mercado e o sistema de livre competição. Ora, o Brasil não chegou a atravessar uma fase de liberalismo econômico em moldes semelhantes aos dos Estados Unidos. Enquanto lá o Estado sempre se absteve de interferir nos mecanismos de mercado, aqui o governo ou se apresentou como patrocinador dos interesses privados ou como atravancador do processo econômico através do regime de privilégios e concessões e de uma mentalidade burocrática cartorial. Passamos, pois, de um sistema semimercantilista diretamente para uma forma de dirigismo econômico, que é o atual. Queimouse a etapa do capitalismo puro e co nosso liberalismo cingiu-se ao plano político-jurídico.

Enquanto as classes empresariais no Brasil se habituaräm à presença intervencionista do Estado, desenvolveu-se nos Estados Unidos verdadeira ojeriza ao poder não apenas estatal mas também privado, em que pese o surgimento das macroempresas (nesse ponto a força de aglutinação das unidades econômicas foi maior do que o medo do poder). Essa diversi- 
dade de tradição e sistemas conduz, portanto, a formas distintas de controlar a atividade nociva do poder econômico. Assim, os mecanismos de controle de preços, de distribuição de alimentos e outros do mesmo gênero, alcançados no Brasil por via direta, poderão ser, também, uma forma de evitar abusos do poder econômico nas respectivas áreas de atuação.

Este "approach" é inconcebível nos Estados Unidos onde, até hoje, se acredita na capacidade de um mercado livre se autocorrigir. Vale lembrar a imensa dificuldade que a administração do Presidente Nixon vem enfrentando para justificar o controle de certos preços, como medida antiinflacionária.

\section{Política antitruste e tipos de mercado}

Por outro lado, o sistema competitivo americano se desenvolveu em função de um grande mercado de que participam grandes unidades empresariais privadas. No Brasil, ao contrário, ainda temos um mercado pequeno composto de grandes empresas, graças à atuação de grupos estrangeiros e do próprio Estado através de empresas públicas e sociedades de economia mista. Em termos de competitividade, o mercado brasileiro poderia, em geral, ser classificado da seguinte forma: (a) não competitivo (áreas restritas à atuação do Estado ou cobertas por poucas empresas privadas que não têm realmente necessidade de competirem entre si, seja porque estão voltadas para o mercado externo, seja porque a demanda do mercado interno é suficientemente ampla para dispensar a concorrência); (b) semicompetitivo (segmento do mercado atendido por um número significativo de grandes empresas nacionais ou estrangeiras que atendem uma demanda interna razoavelmente preenchida); (c) competitivo (grande número de pequenas e médias empresas para um mercado interno razoavelmente saturado).

Mesmo nos setores acima descrito como semicompetitivos e competitivos, não se pode pretender grau de competição em moldes americanos. A intervenção estatal, direta e indireta, se faz muitas vezes para evitar a competição que teria conseqüências danosas do ponto de vista da coletividade. Basta imaginar o que aconteceria se as numerosas empresas nacionais, que ainda operam sem técnicas racionais modernas, mas que empregam parcela ponderável da mão-de-obra (fator de equi-
librio social), passassem a sofrer o ataque das modernas em-
presas multinacionas presas multinacionais altamente sofisticadas $c$ automatizadas. 


\section{A deformação funcional do CADE}

O último aspecto que deve ser salientado é o da deformação funcional do nosso mecanismo repressor. Verifica-se que a atuação do CADE, apesar de ser órgão vinculado ao Poder Executivo, através do Ministério da Justiça, se processa nos moldes de verdadeiro tribunal judiciário, dentro do qual se forma um contraditório terrivelmente complexo e despido da presunção de comando característica doș órgãos da administração direta, como ocorre, por exemplo, com o Conselho Interministerial de Preços. Ora, a meu ver, a repressão de abusos do poder econômico é um dos aspectos do poder de polícia inerente ao Estado; aproxima-se também da sua função fiscal, fundamentada em sistema rígido de subordinação do contribuinte em face do Fisco. Entretanto, tal não se passa com o CADE, seja pelo reduzido prestígio político do órgão, seja pelo receio que inspiram os tribunais administrativos, seja, ainda, devido à própria processualística complicada prevista em lei. De mais a mais, a insuficiência e precariedade do sistema de coleta de informações seguras não permite aos conselheiros a formação de um juízo perfeito de convicção.

\section{III - SUGESTÕES}

Todas as faltas acima apontadas não são suficientes para mudar minha convicção de que um órgão de repressão dos abusos econômicos é não apenas recomendável, mas imprescindivel no Brasil, desde que não se pode presumir pureza absoluta por parte das forças integrantes do nosso mercado. Entretanto, uma política repressiva deveria ser alicerçada em alguns pressupostos básicos, a saber:

a) o comportamento abusivo de grupos econômicos é sempre nocivo aos interesses nacionais e deve ser reprimido sem timidez;

b) os delitos econômicos devem ser identificados dentro do quadro econômico e social do Brasil, sem apego estrito às formas clássicas de abuso em outros países e sistemas econômicos;

c) a função de reprimir cabe primordialmente ao Poder Executivo dentro do nosso sistema político-econômico. 
O primeiro pressuposto merece profunda reflexão, pois não são poucos os que, voltados para o imediatismo dos resultados econômicos, receiam que a política antitruste seja desestimuladora da iniciativa privada. Trata-se de uma imagem cuidadosamente elaborada e "vendida" nos Estados Unidos pelos supergrupos econômicos para os quais a Federal Trade Commission é uma pedra no sapato. Na verdade, porém, a vitalidade do sistema e o respeito que ele inspira a todas as classes econômicas prova exatamente o contrário.

Quanto ao segundo ponto, ou seja a identificação dos focos ou áreas mais prováveis de comportamentos econômicos abusivos no Brasil, decorre da nossa extensão geográfica associada ao desequilíbrio qualitativo e quantitativo do mercado interno, bem como dos aspectos sociais e políticos inerentes a um pais em fase de desenvolvimento.

1. Esse quadro será propício ao aparecimento de ajustes para a divisão de mercados, exclusão de competidores menores e outras formas de comportamento anticompetitivo.

2. Da mesma forma, a participação intensa de empresas multinacionais no nosso mercado interno é outro fator a ser levado em conta, não apenas pelo poder econômico que lhes é inerente, mas também pela dificuldade em estabelecer a prova efetiva de conluio ou acordo anticompetitivos. De fato, como essas empresas operam em escala mundial, os ajustes são, em geral, estabelecidos no exterior e somente apuráveis no Brasil através dos resultados econômicos. Portanto, como se viu anteriormente, a única forma de coibir possíveis abusos será através de um câmbio de mentalidade (da jurídica para a econômica) e de um sistema técnico adequado de levantamento de informações. Para realce da importância desse aspecto do problema, vale lembrar que, ante os abusos praticados por empresas americanas no exterior, o Governo dos Estados Unidos está estudando a criação de um sistema punitivo doméstico aplicável às sociedades que se enquadrem nesta hipótese de delitos praticados fora da sua sede.

No entanto, vários países, especialmente aqueles que dependem em grau elevado de investimentos estrangeiros, receiam impor controles às atividades das empresas multinacionais e ver esses investimentos desviados para paises com legislação permissiva. $\mathrm{O}$ argumento, a meu ver, não tem pro- 
cedência no caso do Brasil, tendo em vista a boa reputação da nossa economia, que por si só assegura atrativos ao investidor estrangeiro. Aliás, quando se criou o controle restritivo ao pagamento de royalties no exterior, as queixas foram muitas e nem por isso diminuiu o ritmo dos novos investimentos.

3. Outra tarefa que poderia ser atribuída ao órgão executor da política antitruste no Brasil é a do controle do dimensionamento das empresas privadas. A "mística" das economias de escala impediu, por algum tempo, que se analisassem com objetividade todas as conseqüências (inclusive as não-econômicas) do crescimento incontrolado das unidades econômicas. Hoje, abandonada a premissa de que dimensão e eficiência guardam relação direta, é possivel tirar algumas conclusões sobre o fenômeno. Por exemplo, a tendência expansionista das empresas visa tanto à redução dos custos por unidade de produção, como também à segurança dos lucros, esta última impedindo a ocorrência de crises cíclicas. Ambos os resultados são logrados através da concentração vertical e horizontal das unidades econômicas. Uma das conseqüências concretas negativas desse comportamento, que se verifica nos Estados Unidos, é a falta de interesse dessas empresas concentradas em aperfeiçoar seus produtos, como ocorre em regime de concorrência mais intensa. De fato, controlando várias fases da produção e da distribuição, a empresa prefere manter a linha de produtos existentes a criar novos, evitando, assim, os custos de pesquisa. Como ilustração, aponta-se o caso da empresa Polaroid, considerada de tamanho médio, e que consegue lançar no mercado produtos (equipamentos de fotografia) bem mais sofisticados e baratos do que os de seus concorrentes maiores.

A segunda resultante da dimensão se verifica no plano político. Como aponta J.K. Galbraith, as macro-empresas, em decorrência da sua participação fundamental na economia nacional, assumem função social, que as aproxima cada vez mais das "responsabilidades estatais". Entretanto, devido ao seu poderio econômico passam a desfrutar também de excessivo poder político, que ameaça escapar ao controle do próprio Estado. Por isso, cogita-se agora,- no Senado americano, de legislação específica para reduzir a dimensão de certos grupos econômicos, através do sistema de "divestiture".

4. Além disso, o advento no Brasil do "capitalismo industrial" está a exigir o controle eficaz e direto da qualidade dos 
produtos industrializados e a proteçãn do consumidor, que, a meu ver, competem ao Poder Executivo dentro do nosso sistema político. Essas funções poderiam ser exercidas pelo próprio $C A D E$, tendo em vista não existir órgão com essa atribuição específica.

5. Finalmente, poderia competir ao CADE, dentro do conjunto de atribuições a ele cometidas pela Lei $n \cdot{ }^{\circ} 4.137$, exercer a função de "controller" das atividades econômicas das empresas públicas e de economia mista. Com a crescente descentralização administrativa, que resulta na criação de novas empresas e de subsidiárias destas, em associação cada vez mais intima com capitais privados nacionais e estrangeiros, essa forma de supervisão deveria ser examinada com cuidado pelo Governo. De, mais a mais, seria viável excluir as empresas públicas e de economia mista da jurisdição do Tribunal de Contas, já eliminando, desta forma, alguns problemas de ordem legal, que 


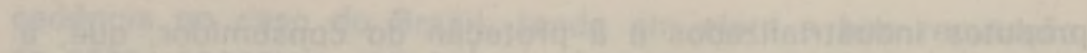

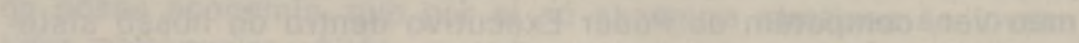

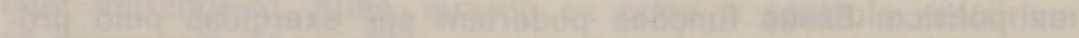

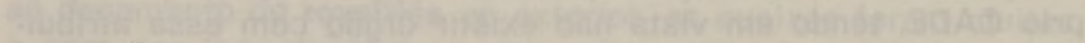
13.

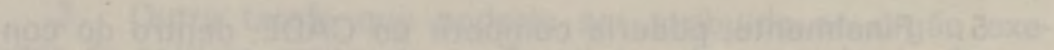

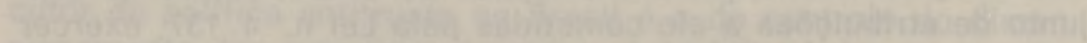

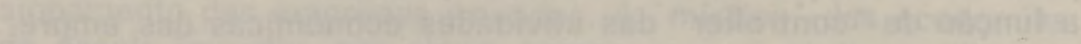
The

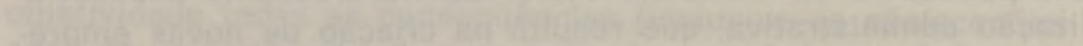

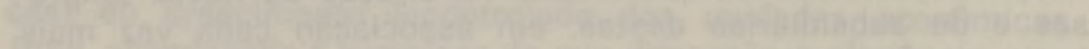

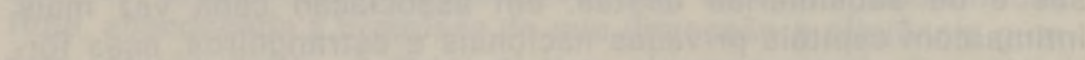

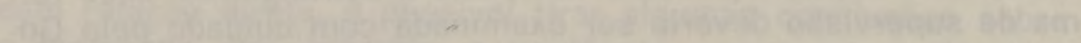

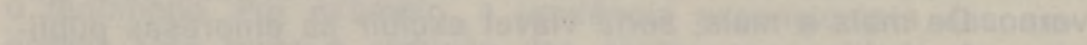

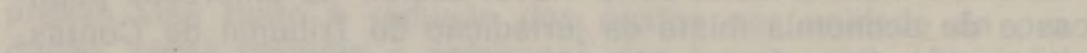

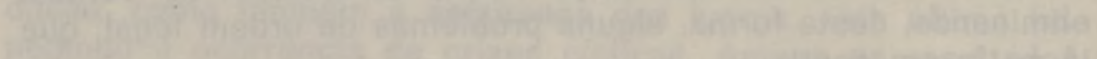

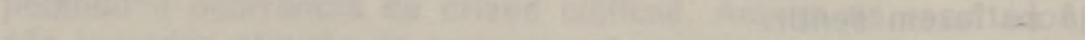

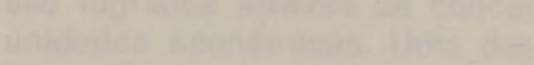

Theras

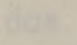

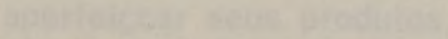

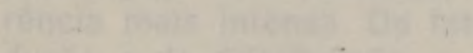

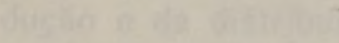

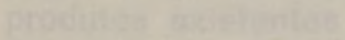

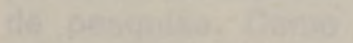

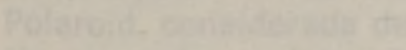

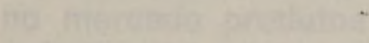

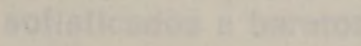

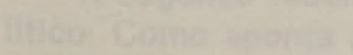

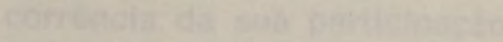

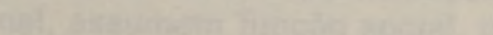

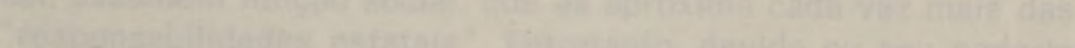

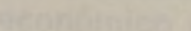

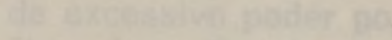

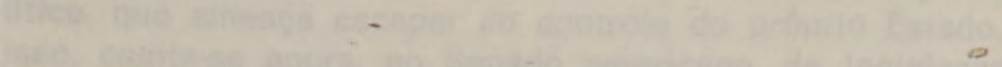

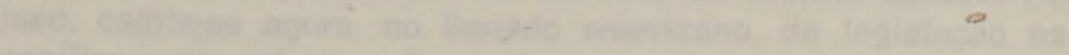

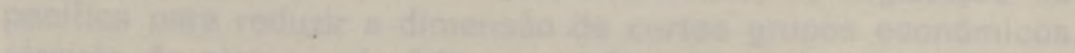

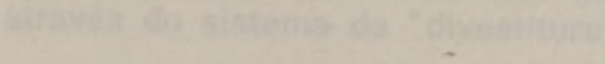

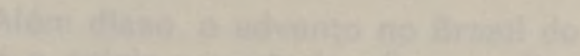

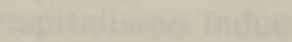

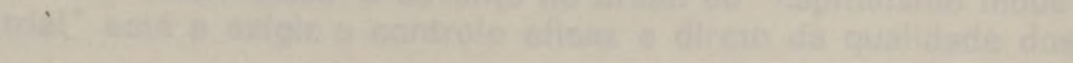

